\title{
Effects on employment of defects in colour vision
}

\author{
W. O. G. TAYLOR \\ Ayr County Hospital
}

The more information which can be fed into a computer the greater its power; similarly we are more efficient as individuals the finer our sense of touch, the greater the range of sounds we can hear, or the closer that two points can be detected separately by the eyes. The finer the discrimination the wider is the information available for action by the intellect. This then is the measure of the value of a fully developed colour sense.

So far as colour is concerned, a majority of people (the trichromats) are able to judge its hue by reference to a three-point standard which allows accurate discrimination of a large variety of hues. A small number*, however, just over 2 per cent. of boys and about $0 \cdot$ I per cent. of girls (the dichromats) have only a two-point standard, and as a result the number of hues that can be discriminated is greatly reduced.

There is also another group, perhaps 4.5 per cent. of boys and 0.3 per cent of girls (simple anomalous trichromats) who, although possessing three-point standards, have these in unusual combination; so that, while perceiving a wide range of hues, they see them differently from the generality. Figs 1, 2, and 3 (after Farnsworth, 1947) express these differences diagrammatically. Such persons also find themselves unable to agree with colour matches accepted by most people, and in their turn make matches inacceptable to the majority.

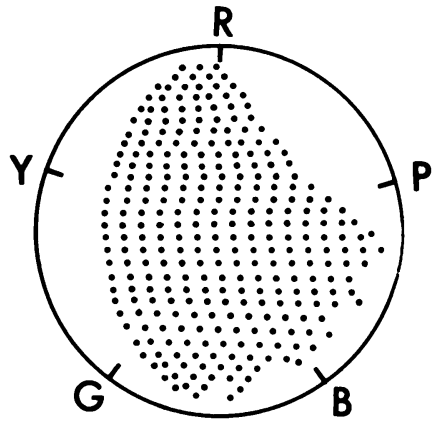

FIG. I The wide range available to the normal

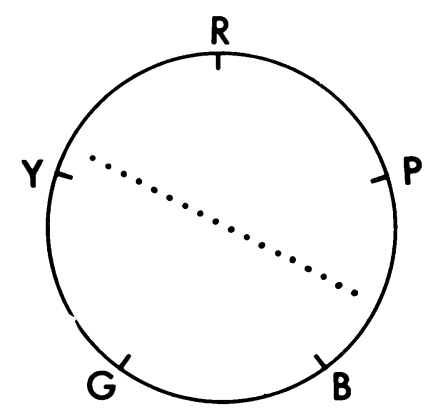

FIG. 2 The much reduced range available to the dichromat (in this case 'green blind)'

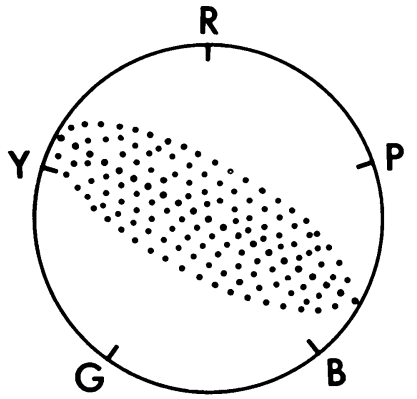

FIG. 3 The intermediate range available to an anomalous trichromat (here 'green anomaly')

FIGS I to 3 Graphic representation of the separate hues discriminable at a particular level of brightness (after Farnsworth, 1947: originals copyright of the Psychological Corporation, New York)

This forms the well-known hue triangle, but it must be remembered that it is only a section across a three dimensional figure, since greater or less brightness introduces a series of similar figures from light to dark, the whole forming the 'colour solid'. $\mathrm{R}=$ red, $\mathrm{P}=$ purple, $\mathrm{B}=$ blue, $\mathrm{G}=$ green, $\mathrm{Y}=$ yellow

Received for publication April 23, 1971

Address for reprints: 16 Ronaldshaw Park, Ayr, Scotland

From a paper read at a Symposium of the British Medical Association (Ayrshire Division) on "Medicine in Industry", February I4, 197 I

*'The figures are given only as an approximation to indicate relative frequencies. But see Kalmus (1965), (.haps 4 and 5 . 
Yet another group (the extreme anomalous trichomats), say 1.5 per cent. of boys and $0 \cdot$ I per cent. of girls, appears to be intermediate between these two, in that they see a diminished range of hues, and can match over a wide range (Fig. 4) which usually includes the matches made by 'normal' people.

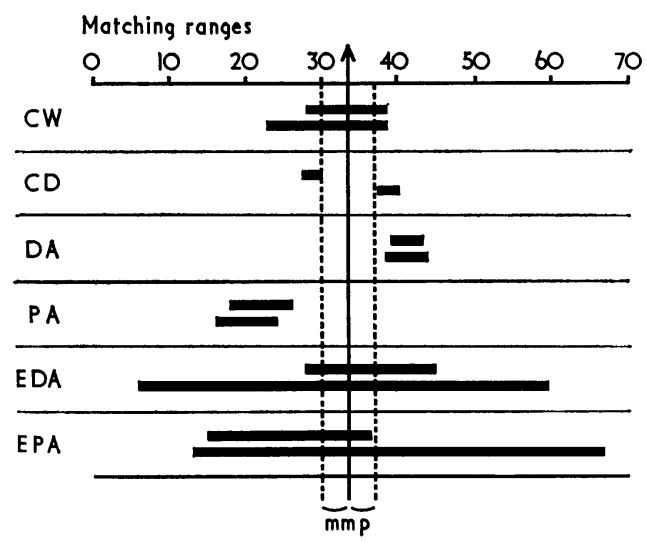

FI G. 4 Matching ranges of various colour defects on a Pickford Anomaloscope

A person with normal colour vision makes matches centred on the vertical line through 35.5 units (on this particular instrument), and the modal matching range is three units. The section marked mmp is the normal range of middle matching point ( \pm 2 S.D.)

$\mathrm{CW}=$ Colour weak

$\mathrm{CD}=$ Colour deviants (these may be only the extreme limits of normal variation, which follows a Gaussian distribution)

PA = Simple protanomaly

DA = Simple deuteranomaly

EDA = Extreme deuteranomaly

$\mathrm{EPA}=$ Extreme protanomaly

Dichromats (whether green or red blind) of course match over the entire range from zero to 72

These different abnormal groups comprise almost one in twelve of the male population.

It is clear that anything which reduces our power to tell different objects apart must be a handicap. What matters, however, is whether the handicap is a significant one, and in particular, whether it influences the ability to follow any particular occupation.

The handles of scissors are shaped to suit the right-handed persons who comprise the majority of the population (Figs 5 and 6) and are really quite awkward for the left-handedo Had the proportions of the left and right-handed in the population been the other way round, the scissors would have been shaped accordingly.

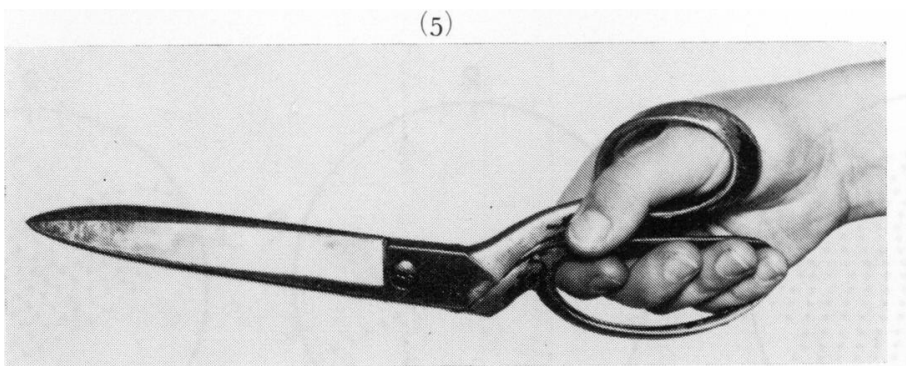

(6)

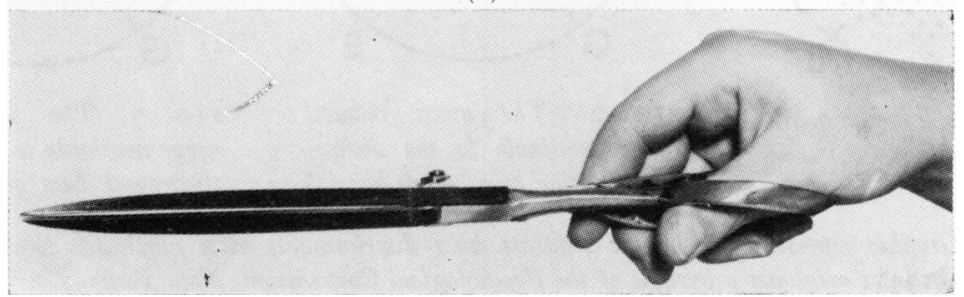

FIGS 5 and 6 Scissors are for the right-handed

Similarly, had 92 per cent. of the population used only a 2-colour system for detection of hue and the remaining 8 per cent. been a somewhat freakish group seeing differences where the 'normal' population saw none, then our use of colour in industry and commerce 
would have developed very differently. Probably a great deal more reliance would have been placed on the other variables, especially luminosity ('brightness').

Unfortunately for the 2-colour and the distorted 3-colour people, the world is not so constructed and they may thus be faced by material disadvantages. The commonest disability is the confusion of red and green, and these are precisely the colours most frequently used to indicate danger on the one hand and safety on the other. Instances of railway accidents due to such defects were found soon after the introduction of a signalling system (Wilson I855); and Nettleship (1913), in a rather amusing little book, reviews the evidence. He quotes the case of a Swiss engine-driver in the 1870 os who appears to have been colour blind. He had no great trouble while he had a normal fireman, but when he was joined by a colour-blind fireman, he was in trouble. This driver was able to distinguish green from white only by the greater brightness of the latter, while the red lamp was so difficult that its 'colour was almost undistinguishable until he was too near it to stop his engine' in time. He claimed to be able to imitate the three signal colours by turning the wick of his (oil) lamp more or less up or down, thus varying its brightness, while he compared it with the approaching signal. This would certainly not be possible at today's speeds. There is no record that he had any serious accident, despite his disability, although he was frequently fined for breaches of the regulations. It is strange that the authorities in most countries seemed reluctant to introduce legislation against this danger. Even after an accident had occurred and a question of misreading signals arose, no effort seems to have been made by the judiciary to check the colour vision of those testifying to the colour of the signal lamps displayed (and witnesses as well as those accused should of course be tested). Apart from reluctance by employers to lose, or to exclude otherwise suitable men, a major reason may well have been the lack of an easily applied and reliable test until comparatively recently.

Even in 1897, a man involved in an accident was examined by the Board of Trade with the inefficient Holmgren Wool test. It was not until the 2oth century that simple tests of reasonable accuracy such as the Ishihara test became generally available.

However slow the acceptance of the dangers of colour defect may have been, it is not unlikely that modern techniques have increased the difficulties for the colour-blind. The use of colour-coding makes processes simpler or safer for the colour-normal but, unless they are specially thought-out with colour deficiency in mind, they make the former's task more difficult or impossible. The first necessity is to identify those at hazard.

\section{Present investigations}

Since 1962 this identification has been attempted in Scotland during the school years. The techniques employed (see Appendix) and the standards adopted have been given in previous papers (Taylor, I966, I970a) and will not be repeated here. Roughly 20,000 children have been tested by school medical officers in Ayrshire since i 963 , most of them at routine school examinations at age 12 or 13 , but some at other ages. Those failing an Ishihara test were then referred to my advisory clinic for full analysis.

Any child, whose colour vision was doubtful to either teacher or parent, was also seen; no accurate estimation of the frequency can be made since the underlying population is not precisely known, and some 2 to 5 per cent. each year failed to attend in spite of being given repeated opportunities.

\section{Material}

Between 1965, when this advisory clinic was started, and late 1970, 904 children were examined. Of these seventy had no significant colour defect whatever, and three had 
apparently a blue-yellow defect (not fully tested), leaving $83_{1}$ ( 776 boys and 58 girls) witho red/green deficiency. In all cases enquiry was made as to the career proposed, and advice was proffered as to what action should be taken after any defects had been diagnosed.

The distribution of defects is set out in Table I.

Table I Type of colour defect,

by sex

\begin{tabular}{lccc}
\hline Defect & & Male & Female \\
\cline { 1 - 1 } PPA & & 107 & I \\
PA & & 40 & 2 \\
& 49 & & I
\end{tabular}

Colour blind

D

EDA

DA

\begin{tabular}{|c|c|c|}
\hline Colour weak & II & Io \\
\hline $\begin{array}{l}\text { Low colour } \\
\text { discrimination }\end{array}$ & 18 & Io \\
\hline $\begin{array}{l}\text { Blue/yellow } \\
\text { defect only }\end{array}$ & 2 & I \\
\hline
\end{tabular}

$\mathbf{P}=$ Protanopia

EPA $=$ Extreme protanomaly

PA $=$ Simple protanomaly

$\mathrm{D}=$ Deuteranopia

EDA $=$ Extreme deuteranomaly

$\mathrm{DA}=$ Simple deuteranomaly

Colour weak-Middle matching point normal but range wide ("insensitive")

Low colour discrimination-Poor judgement of colours near each other in hue

(severe red blindness)

(moderate red blindness)

(complete green blindness) (moderate green blindness)

The first group, 'colour-blind', contains those usually considered in this context, buto the 'colour weak' and those with 'low colour discrimination' have also to be considergd" in the light of their future occupation.

The children's ages at the time of the examination ranged from 10 to 18 years, with about two-thirds being aged 13 or 14 years.

As would be expected the percentage who had decided on a future career increased fairly steadily with age (Fig. 7). About half were at the end of their primary schoolinga and the rest in their last year or so at secondary school.

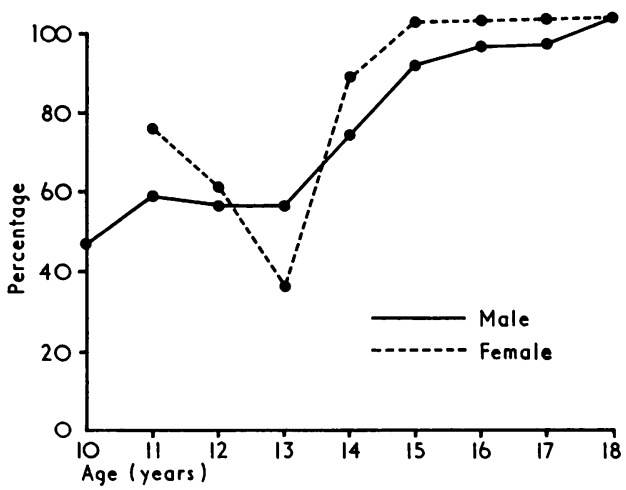

FIG. 7 Percentage of colour-defective children. by age at examination, who had decided on a possible career

\section{Classification of careers}

Since colour blindness is rare in girls, the percentages in their cases may be distorted by the very small numbers. The 75 per cent. at age 11 represents three girls out of only four seen at this age.

From those who had chosen, a division was made into "suitable" and "unsuitable", basedo on the recommendations of the Careers Bulletin of the Youth Employment Service, aftero due consideration of the degree of disability found in relation to the particular careero suggested (Table II, opposite). 
Table II Choice of career, by age and sex

\begin{tabular}{|c|c|c|c|c|}
\hline \multirow{2}{*}{$A g e(y r s)$} & \multicolumn{2}{|l|}{ Male } & \multicolumn{2}{|l|}{ Female } \\
\hline & Suitable & Unsuitable & Suitable & Unsuitable \\
\hline 10 & 3 & 12 & - & - \\
\hline I I & 14 & I5 & o & 3 \\
\hline 12 & 16 & 20 & 3 & 7 \\
\hline 13 & 42 & 55 & 2 & I \\
\hline 14 & 86 & 164 & 4 & 9 \\
\hline I 5 & 22 & 31 & 3 & 6 \\
\hline 16 & 5 & 9 & - & - \\
\hline 17 & 9 & 18 & 2 & I \\
\hline 18 & 2 & 4 & I & o \\
\hline Totals & 199 & 328 & 15 & 27 \\
\hline
\end{tabular}

The kinds of career considered unsuitable were then divided into those in which colour defect can be considered a minor handicap, a major handicap, or a definite bar (Table III).

Table III Adverse effects of colour defects on choice of occupation

\begin{tabular}{|c|c|c|c|c|c|c|}
\hline \multicolumn{6}{|l|}{ Handicap } & \multirow{3}{*}{$\begin{array}{l}\text { Definite bar } \\
\text { Navigation }\end{array}$} \\
\hline \multicolumn{3}{|l|}{ Minor (8I) } & \multicolumn{3}{|l|}{ Major (145) } & \\
\hline Agriculture & (e.g. & Gardener) & Agriculture & (e.g. & Fruit trials officer) & \\
\hline Teaching & (e.g. & Geography) & Teaching & (e.g. & Chemistry) & Traffic control \\
\hline Textile & (e.g. & Dressmaker) & Textile trade & (e.g. & Carpet designer) & Radio-telegraphy \\
\hline Retail trade & (e.g. & Draper) & Retail trade & (e.g. & Butcher) & $\begin{array}{l}\text { Electrical work } \\
\text { (post-office and } \\
\text { Railway }\end{array}$ \\
\hline Service & (e.g. & Driver) & Service & (e.g. & Electrician) & Officer in Forces \\
\hline Armed Forces & (e.g. & Artillery) & Armed Forces & (e.g. & Medical officer) & Police \\
\hline
\end{tabular}

Some careers, such as teacher, are too vaguely described and must be more exactly specified (Table IV), while others, although possibly containing elements where a colour defect would be a handicap—such as 'market gardener', should be more closely defined (Table IV), when it may be possible by eliminating the risk to follow the career after all.

Table IV Careers requiring further definition

\begin{tabular}{lll}
\hline $\begin{array}{l}\text { Career not adequately } \\
\text { specified (43) }\end{array}$ & & $\begin{array}{l}\text { Exact task not } \\
\text { specified }(56)\end{array}$ \\
\cline { 1 - 1 } With animals & & Farming \\
Teaching & & Marine Engineering \\
A trade & Retail trade \\
A profession & Physicist \\
\hline
\end{tabular}


The Tables refer primarily to the degree of difficulty likely to be encountered in particular occupation, which has then to be weighed against the subjects' degree o defect. The occupations quoted are by no means exhaustive, including only those suggested to me by the children. Of course, the career suggested by any boy is obviouslyo strongly conditioned by what he believes to be available (quite apart from the cases in which he proposes to follow his father's occupation). For example, a boy living in Kilmarnock may choose to be a cooper because of the existence of a large firm of whisky distillers in his town.

Further examples may be obtained from the 'Report on Defective Colour Vision in Industry' (Physical Society, I946) and the 'Careers Bulletin' of the Youth Employmen Service ( I 966, i 968). Although 355 children had chosen an unsuitable career, 389 careers: were involved, since 34 had given alternative (and also unsuitable) careers. A further tenchildren had given an alternative which was suitable.

Difficulties in the careers shown in the first two categories in Table III may be encount ered even with fairly minor degrees of colour defect, although the particular occupation may still be possible, at a cost in extra effort. Awareness of the exact nature and extent of the defect is of material assistance to this end. It is also to be remembered that what is a major handicap during the training period may only be of minor significance once the्w individual is trained-it may be possible to avoid branches of an industry in which the을 defect is vital—such as to avoid specializing in skin disease if one is a doctor of medicine, to use instrumental methods to detect colour end-points if one is a chemist; or to becomeo boss of the firm and get others to do the colour-matching if one is a painter and decorator.

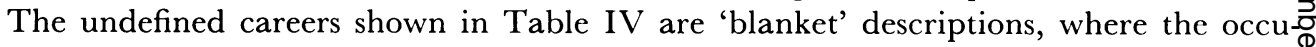
pation suggested has many branches, some of which are unsuitable but some perfecty safe for the colour-blind.

The occupations in which the exact task involved needs to be specified are also shownôंn Table IV. An example is a storeman in a carpet factory who had to hand out wools Faso required. It was ascertained that these were all numbered, but of course the man who dyed this wool to specification, the man who approved the matching between successive batches, the man who chose them from the colours in the designer's cartoon, and the man $\frac{\mathbb{D}}{\mathbb{D}}$ who put on the numbers all required accuracy of colour perception. This is the kind of problem which could be answered by a 'Trade Test' - in which the appointee is aslled to perform operations similar to those which he would have to carry out in practice (Wright, I964).

Two provisos must be made if 'Trade Tests' are adopted (Taylor i 97ob):

(r) The conditions must be those encountered in the works-if cables can sometimes be dirty or lighting poor, then must they be so in the test.

(2) The results are not to be regarded as of general application, but only to the trade tested.

An example of this was given by Sloan and Habel (1955), in discussing the requirements for air-crew, which also shows the difference between wide-field and point-source stimu N lation (stimulating a wide area of the retina or only the fovea).

The last group includes the occupations which are completely ruled out by colourn defect (Table III).

Advice to patients

After diagnosing the presence, nature, and extent of the defect, and having ascertained $\stackrel{\mathbb{N}}{?}^{\circ}$ 
the type of career proposed, what advice should be given? As suggested earlier, this may vary with the stage in that career, so the advice should take cognisance of:

(I) The effect of the defect on schooling;

(2) The effect during the period of training;

(3) The effect on performance in the actual task;

(4) The safety factor-car driving or sailing a boat after dark.

Throughout this consideration, a due sense of humility must be preserved. Except in the careers where any significant error is a bar or the lives of others may be endangered, the frequency of the triumph of determination over difficulties must be remembered.

The fact of the defect should be made clear to the boy and his parents, the problems that it is liable to lead to in his suggested career should be mentioned, and possible alternatives should be suggested or reference made to the careers officer.

Having given all this advice, is any notice whatever taken of it? I began to wonder when I reviewed one of my former patients. This boy, now I 7, was found in March, I 968 , to have a simple deuteranomaly. At that time his stated career was "teacher of history"--perfectly suitable-however he left school early and was employed as a trainee electrician! This sounded quite unsuitable but on closer questioning it was found that in fact his work was assembling components of switch-gear in a factory, all shining colours of pristine freshness under fully adequate lighting and all parts presented in separate trays to facilitate the operation.

It will have been noted there were only 224 suitable choices of career out of 6 i 3 choices made. That is, two out of three colour defective boys choose badly. In r966 I had already noted that more than half of the choices were unsuitable. I wondered then whether there was something about colour blindness which made the subject gravitate towards the wrong career.

I still wonder.

\section{Summary}

In the course of examining 83 I Ayrshire school children with deficiency in red-green vision, a decision had to be made as to the suitability of suggested future careers. Recomendations were made concerning future difficulties or dangers, and the basis upon which these suggestions may be made are discussed.

I am indebted to Mr. G. Donald, D.A. Senior Lecturer, Department of Medical Illustration, Glasgow University, for the figures.

I have also to acknowledge the assistance of my colleague Dr. K. Ahmad in 1969 and 1970 with the Ioo-Hue and pseudo-isochromatic tests.

\section{Appendix}

\section{Tests used}

I. PSEUDO-ISOCHROMATIC PLATES

Ishihara

Tokyo Medical College

American Optical (H.R.R.)

Farnsworth $\mathrm{F}_{2}$ 
II. ISOGHROMATIC DISGRIMINATION TEST

Farnsworth's I00-hue Test.

III. ANOMALOSCOPES

Nagel, Model II

Pickford (1966) Model

\section{References}

CAREers BULletiN (1966) Youth Employment Service, Spring Issue. H.M.S.O., London (1968) (Amendments)

farnsworth, D. (1947) “Manual Dichotomous Test for Color Blindness, Di5 Panel". Psycho- $\frac{\vec{\omega}}{\omega}$ logical Corporation, New York

Kalmus, н. (1965) "Diagnosis and Genetics of Defective Colour Vision". Pergamon Press, Oxford응.

NETTleship, E. (1913) “Accidents from Defective Sight". Adlard, London

PHYsical society (1946) (Colour Group Committee) "Report on Defective Colour Vision in:

Industry". London

SLOAN, L. L., and habel, A. (1955a) F. opt. Soc. Amer., 45, 592, 599

TAYLOR, W. O. G. (1966) Trans. ophthal. Soc. U.K., 86, 59 I

- (1970a) Ann. Ophthal. (Chicago), 2, 184

(1970b) "Standardization of Conditions for Colour Vision Testing" (Paper read before

meeting of colour group of Great Britain (Scottish Section) Paisley, October 14, 1970) (Not yet published)

wiLson, G. (1855) "Researches on Colour-Blindness, with a Supplement on the Danger attending

the Present System of Railway and Marine Coloured Signals". Sutherland and Knox, Edinburgh $\vec{\bullet}$

(Quoted by Nettleship, I913, p. 2).

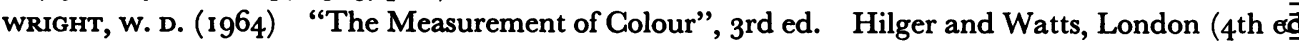
1969, Hilger, London) 